УДК 342

DOI 10.18413/2712-746X-2020-44-2-359-365

\title{
Историко-правовые аспекты возникновения и развития института выборов в дореволюционной России
}

\author{
Вородюхин С.Е., Лысенко В.А. \\ Белгородский юридический институт Министерства внутренних дел \\ Российской Федерации имени И.Д. Путилина, \\ Россия, 308024, Белгород, ул. Горького, 71 \\ E-mail: vorodyuhin-stani@mail.ru; lisenko.vik.2013@yandex.ru
}

\begin{abstract}
Аннотация. Представлен краткий анализ основных нормативных правовых актов, регулирующих процесс выборов на основных этапах российской истории, их организацию и управление конкретной выборной системой. Отмечается, что конкретно-исторические этапы и формы российских выборных институтов и избирательный процесс всегда существенно связаны с политико-правовой системой власти. Генезис и специфика российского избирательного права связаны с историческим развитием правоохранительных органов, обеспечивающих безопасность и право избирать и быть избранным. Этот процесс неизбежно приводил к формированию традиций и накоплению правового и организационного опыта в этой сфере деятельности. Выборы должны быть не только политическим, но и социально-культурным институтом. Опыт прошлого становится очень интересным, так как институт выборов в России представляет собой не только политическое выражение активной части населения, но и инструмент постоянной реформы власти.
\end{abstract}

Ключевые слова: выборы, обычаи, договоры, приказы, Земский собор, Боярская дума, Сенат, магистраты, губернские и уездные земские учреждения, Государственная дума.

Для цитирования: Вородюхин С.Е., Лысенко В.А. 2020. Историко-правовые аспекты возникновения и развития института выборов в дореволюционной России. NOMOTHETIKA: Философия. Социология. Право. 45 (2): 359-365. DOI 10.18413/2712-746X-2020-44-2-359-365

\section{Historical and legal aspects of the origin and development of the election institute in Russia}

\author{
Sergey E. Vorodyukhin, Victoria A. Lysenko \\ Belgorod Law Institute of Ministry of the Internal \\ of the Russian Federation named after I.D. Putilin, \\ 71 Gorky St, Belgorod, 308024, Russia \\ E-mail: vorodyuhin-stani@mail.ru; lisenko.vik.2013@yandex.ru
}

\begin{abstract}
The article contains a study of the main historical stages of the formation and development of the electoral Institute in Russia. The authors of the article give a brief analysis of the main normative legal acts regulating the election process at the main stages of Russian history, their organization and management of a specific electoral system. It is noted that historical facts show that the specific historical stages and forms of Russian electoral institutions and the electoral process are always significantly connected with the political and legal system of power. The Genesis and specifics of Russian electoral law are related to the historical development of law enforcement agencies that ensure security and the right to vote and be elected. This process inevitably led to the formation of traditions and the accumulation of legal and organizational experience in this field. Elections should be not only a political, but also a socio-cultural institution. The experience of the past is now becoming very interesting, since
\end{abstract}


the institution of elections in Russia is not only a political expression of the active part of the population, but also an instrument of permanent reform of the government.

Keywords: elections, customs, treaties, orders, Zemsky Sobor, Boyar Duma, Senate, magistrates, provincial and district zemstvo institutions, State Duma.

For citation: Vorodyukhin S.E., Lysenko V.A. 2020. Historical and legal aspects of the origin and development of the election institute in Russia. NOMOTHETIKA: Philosophy. Sociology. Law series. 45 (2): 359-365 (in Russian). DOI 10.18413/2712-746X-2020-44-2-359-365

\section{Введение}

Институт выборов является фундаментом каждого современного демократического государства. В настоящее время сложно представить нашу жизнь без выборов, так как они представляют собой политический институт, который позволяет народу стать настоящим источник власти, а гражданскому обществу контролировать эту власть.

Очень часто в оппозиционной медийном дискурсе воспроизводится мнение, что у России нет собственных демократических традиций, отсутствует «гражданское общество», что само по себе якобы требует заимствования «западных демократических институтов», в том числе западного избирательного права. Однако даже краткое обащение к истории российской политико-правовой системы свидетельствует об обратном: на всём протяжении тясячелетней истории мы обнаруживаем устойчивые традиции существования выборных институтов и органов, которые создавались самими русскими людьми разных сословий и классовых групп и всегда были связаны с основными властными и общественными институтами, влияли на их непосредственную деятельность [Иванченко, 1996; Кононов, 1999; Минникес, 2016].

При всей значимости проблемы, история выборных институтов в российском государстве досоветского периода до сих пор слабо изучена именно по причине влияния на юридическую науку и историческое знание предвзятых стереотипов общественного мнения, сформированного под влиянием западнической идеологии ещё со времён начала XIX века. Однако на этом фоне выделим работы таких ученых, как В.П. Заботина, И.В. Минникес, Ю.П. Титова и других, которые внесли существенный вклад в развитие историографии проблемы. Стоит отметить, что историко-правовые аспекты возникновения и развития института выборов в России на каждом конкретном историческом этапе рассматривались весьма фрагментарно.

\section{Основная часть}

Летописные и исторические документы свидетельствуют, что уже в IX-XII веках в Русском государстве выборы играли важную роль в развитии общества, а демократические начала для данного периода были характерны на всей территории исторической Руси. Особое значение при этом имеет факт наличия в этот период института вече и вечевого права как существенного индикатора нашего национального и культурного «народоправства» [Пузанов, 2001, с. 48]. При этом древние русичи руководствовались не только обычаями, но и договорами, тем самым принимали активное участие в управлении обществом и государством. Договор между князьями и горожанами почти во всех городах Руси регулировал не только сам факт выборности князя, но и доминирование вече как основного демократического, общинного института над субъектом, носителем феодальной власти. Можно сослаться на событие 1196 года, когда свободные новгородцы закрепили собственное право на выборность князя по воле городской общины и в её интересах. В летописи мы читем: «А Новъгородъ выложиша вси князи въ свободу, да есть Новъгородъ свободенъ, и где хотятъ Новогородци, и оттуду себе князя взимаютъ» [Полное собрание..., 
2000, с. 30]. Один этот факт перечёркивает все предвзятые мнения о том, что в отечественной традиции якобы отсутствовало демократическое избирательное начало: наоборот, в этом плане мы вовсе не уступали феодальной Европе, но обладали собственнйо демократической избирательной системой.

В периоды феодально-вотчинной раздробленности, а затем и формирования единого русского централизованного государства избирательные институты ассоциировались с ростом и влиянием княжеской власти, однако процесс усиления власти сопровождался параллельным развитием вечевых институтов [Сергеевич, 2004]. Важно отметить и тот факт, что само вече было представительным (выборным) органом и институтом самоуправления горожан (как и общинный сход на селе), который самостоятельно организовывал различные мероприятия, связанные с назначением, проведением и контролем выборов его состава.

В дальнейшем выборные институты в России продолжили развиваться в XVI и XVII веках (вплоть до петровских реформ) на первых этапах возникновения и укрепления монархии, когда наблюдение за выборными процедурами выполнялись должностными лицами административных и судебных органов. В частности, возникает такой административный орган, как «Разбойный приказ», который следил за выборами «губных старост» и за должным отправлением ими своих обязанностей. И хотя губные старосты избирались из дворяского и боярского сословий (из числа грамотных их представителей), но само их избрание и утверждение в должности зависело от «земель», и они были важным фактом развития земской демократии и одновременно институтом уголовной юрисдикции и системы безопасности (прообразом будущей полиции). Избирались они на неопределённый срок (часто на год), утверждались и приводились к присяге Разбойным приказом, но отвечали не только перед ним, но и перед земскими избирателями и исполнительной властью земства (воеводами).

В этот же период развивается вся система земского самоуправления, опирающаяся на выборных земских старост, целовальников (лучших людей) и земских судей. В земских «избах» (налоги московских приказов) для осуществления делопроизводства избирались земские дьяки. Разбойный приказ также контролировал порядок выборов и деятельность земских и губных органов местного самоуправления. Большое значение было уделено местному самоуправлению, поскольку территория Московского государства увеличивалась, а также шла борьба между государственной властью и боярством.

XVII век, как считает И.В. Минникес [2011], являлся сочетанием обычного права и нормативно-правового регулирования выборов. Земские соборы играли особую роль в развитии государства и права России в данный период, так как они рассматривали вопросы внешней и внутренней политики, законодательства, налогов и пошлин. Верховным сословно-представительным органом был двухпалатный Земский собор, в который входили представители всех российских сословий (кроме крепостных крестьян, которых было вопреки стереотипам не так уж и много). Верхнюю палату, которую составляли Боярская Дума (боярская элита) и Освящённый собор (основные иерархи Православной Церкви), возглавлял лично царь. В нижнюю палату избирались как «государевы служивые люди», так и представители других слоёв дворянства, купечества и мещанства, порой и зажточных крестьян. Очевидным был своеобразный «имущественный ценз», что снижало эффект выборности, но, тем не менее, Земский собор был успешной формой, позволяющей представителям разных сословий участвовать в обсуждении и решении государственных дел. Именно Земский собор во многом решил судьбу русского царства в период и после Смуты конца XVI и начала XVII веков.

На рубеже XVII-XVIII веков с восшедствием на царский трон Петра I в России учреждается неограниченная, самодержавная монархия (и в этом мы шли параллельно развитию монархий в Западной Европе). Этот период характеризуется таким явлением, как усиление управления бюрократическим принципом в ущерб избранному общинному 
принципу. Земские соборы были упразднены, что и свидетельствовало о ликвидации остатков сословно-представительных органов. В.О. Ключевский в своих трудах пришел к следующему выводу: «История Земского собора в XVII в. есть история его разрушения», потому что «земское представительство пало вследствие усиления централизации в управлении и государственного закрепощения сословий» [Ключевский, 1988, с. 199]. Е.В. Анисимов считает, что прекращение созыва Земских соборов и законодательное оформление крепостного права неизбежно отражалось как на системе права и юстиции, так и на юридическом статусе всех подданных царя [Анисимов, 1999]. В эпоху правления Петра I вместо представительского Земского собора и такого важного органа, как Боярская Дума, учреждается Правительствующий Сенат, члены которого уже назначались императором и выполняли сугубо законосовещательные функции.

Петр I ликвидировал не только Земские соборы, но и упразднил земское «губное представительство», передав управление на местах воеводам, высшей исполнительной и полицеской власти. Дворянские советы при воеводах хоть и избирались уездными дворянскими собраниями, но выполняли сугубо совещательные функции. Специальные органы, которые бы осуществляли проведение этих выборов и контроль над ними, не образовывались [Избирательные комиссии..., 1996], а всё было сосредоточено в руках воевод, то есть исполнительная власть делала фикцией сам принцип выборности в России того времени.

Екатерина II, издав манифест о создании комиссии для составления Уложения 1766 года, расширяет избирательные права. В её Указе от 11 декабря 1773 г. «О правилахъ выбора Судей въ Магистраты и Ратуши» [Полное собрание..., 1830, с. 869] учреждаются достаточно широкие правила выборности территориальных органов управления. П.И. Любличинский отмечат: «...в этом акте мы впервые находим более разработанные нормы общего избирательного права и, в частности, нормы, направленные к ограждению выборов от различных злоупотреблений» [1906, с. 158]. Однако «демократические реформы» Екатерины II под влиянием революционной смуты в Европе были свёрнуты и не реализованы.

B XIX веке произошли важные для нашего отечества реформы, которые не могли не отразиться на структуре проведения выборов в России. Данный институт подвергся тоже значительным изменениям, прежде всего это связано с проведением земской (1864 г.) и городской (1870 г.) реформ. В земских органах были более значительные преобразования. Кардинальным образом в этот период изменилась система органов местного управления. Губернии возглавлял губернатор, который в свою очередь подчинялся Министерству внутренних дел [Кононов, 1999, с. 44]. Александр II создал систему местного представительства (посредством курий) на основе имущественного ценза, утвердив 1 января 1864 года «Положение о губернских и уездных земских учреждениях». Земские представительные органы, таким образом, носили в пореформенный период весьма ограниченный характер, но стали важным шагом на пути формировании в России предпосылок для нового избирательного права (прямого и косвенного).

Впоследствии по аналогичной системе земской реформы была проведена и реформа городского самоуправления. Это позволило сформировать местное самоуправление в городах: городские жители выбирали городские думы, которые в свою очередь создавали городские управы, выступали в качестве исполнительных и административных органов. При этом избирателями были исключительно состоятельные налогоплательщики, которые имели неоспоримое преимущество на выборах. Это и объясняет небольшое количество избирателей [Карева, 2018]. Новые органы местного самоуправления занимались главным образом экономическими вопросами: благоустройством дорог, школ, больниц, регулированием местной торговли и промышленности, организовывали санитарные и противопожарные мероприятия, контролировали здравоохранение и просвещение населения. Выборы в это время регулировались актами на основе общих норм и избирательных законов, которые периодически включали избирательные нормы высшей юридической силы 
[Минникес, 2011]. Таким образом, в XIX веке процедура выборов усложнилась, и наблюдался значительный рост населения, участвующего в выборах.

В начале XX века серьезно обострилась политическая ситуация в стране, и возникла объективная потребность в изменении существующего права, чтобы создать условия для дальнейшего развития демократических институтов выборов. Особую роль здесь сыграли «Манифест об учреждении Государственной думы» и «Положение о выборах в Государственную Думу», «дарованные» в августе 1905 года Николаем II под давлением революционных событий и поражения в русско-японской войне [Российское законодательство..., 1994]. Дальнейшая демократизация политико-правовой жизни связана с «Манифестом об усовершенствовании государственного порядка» от 17 октября 1905 года, в котором отмечалось, что Государь учредил новый представительный орган - Государственную Думу, «повелев подлежащим властям принять меры к устранению прямых проявлений беспорядка, бесчинств и насилия, и охрану людей мирных, стремящихся к спокойному выполнению лежащего на каждом долга: привлечь к участию в Государственной Думе те классы населения, которые ныне совсем лишены избирательных прав» [Анисимов, 1999, c. 188]. С этим было связано принятие 11 декабря 1905 года закона «Об изменении положения о выборах в Государственную Думу» [Анисимов, 1999, с. 188]. Однако эта избирательная система имела существенные ограничения, так как оставалась цензовой в плане активного и пассивного избирательного права и всецело контролировалась Министерством внутренних дел, которое, согласно п. 11 «Положения о выборах в Государственную Думу» 1905 года, через полицию составляло списки избирателей и определяло выдвижение на съезды городских избирателей уезда. В то же время в соответствии с этим положением лица, занимавшие полицейские должности, не участвовали в выборах, и таким образом правительство стремилось «защитить» полицию от вовлечения их в политику.

А.Х. Денильханов отмечает: «... первые в стране свободные и демократические выборы без использования избирательных технологий и административного давления привели к созданию представительного и адекватного по интеллектуальному уровню, работоспособного парламента» [2018, с. 121]. Но если бы это было так, то не последовал бы роспуск первой Государственной Думы и обострение революционных процессов в стране. Это привело к тому, что 3 июня 1907 года было принято новое «Положение о выборах в Государственную Думу» с разъяснениями Правительствующего Сената и Министерства внутренних дел [Российское..., 1994]. Но и здесь организацию и проведение выборов контролировал отдел Особого делопроизводства департамента полиции (структурная часть Министерства внутренних дел), который готовил инструкции и объяснения, которые утверждались Советом министров и императором. Например, пункт 2.3 Положения о выборах гласил: «общий надзор за надлежащим проведением выборов под руководством Министерства внутренних дел возлагается на губернаторов или градоначальников по принадлежности», которые имели право фильтровать информацию о подготовке и ходе выборов с мест, регулировали избирательные процедуры и весь ход выборов.

На основе этого Положения создавались специальные комиссии по рассмотрению вопроса о правильности выборов. Данный орган состоял из двух членов, занимающих должность судьи, и до пяти членов администрации (включая сотрудников полиции). Судебные разбирательства велись негласно, на основании письменных материалов. В законе не определены основания, которые могли бы послужить основанием для кассации выборов, и поэтому его апелляционная проверка была в основном поверхностной, а основным в избирательном праве оставался нормативно-правовой акт, никак не закреплённый конституционно [Минникес, 2011, с. 208]. Очевидно, что преобладание исполнительной власти над выборной имело в России глубокие корни и предпосылки.

Революция в феврале 1917 года явилась новой вехой в истории избирательного права России. Во Всероссийское Учредительное собрание были проведены выборы, и в результате демократического голосования были избраны органы земского и городского самоуправ- 
ления. Закон о выборах в России был самым современным государственно-правовым документом того времени. Исходя из этого, Учредительное Собрание было избрано 12 ноября 1917 года, но оно просуществовало недолго, так вступило в противоречие с новым типом представительной власти и народоправства, каковыми первоначально были Советы, также имевшие свои предпосылки в истории и традициях российского избирательного права.

\section{Заключение}

Таким образом, выборы должны быть не только политическим, но и социальнокультурным институтом. Опыт прошлого в настоящее время становится очень интересным, так как институт выборов в России представляет собой не только политическое выражение активной части населения, но и инструмент постоянной реформы власти и контроля над ней со стороны общества.

\section{Список источников}

1. Антология мировой правовой мысли. 1999. В 5 т. Т.5. Россия конец XIX - XX в. М., Мысль, 829 с.

2. Ключевский В.О. 1988. Соч. В 9 т. Т. 3: Т. 3. Курс русской истории. Ч. 3.414 с.

3. Полное собрание русских летописей (ПСРЛ). Т. 10. М., ЯРК. 2000. 248 с.

4. Полное собрание законов Российской империи с 12. 1649 года. Т. ХІХ. 1770-1774. СПб.: типография II Отделения Собственной Его Императорского Величества Канцелярии, 1830. $1081 \mathrm{c}$.

\section{Список литературы}

1. Анисимов Е.В. 1999. Дыба и кнут. Политический сыск и русское общество в XVIII веке. М., Новое литературное обозрение. 720 с.

2. Денильханов А.Х. 2018. Зарождение российского парламентаризма: к вопросу о выборах в I-IV Государственные Думы Российской империи. Власть, 26(4): 116-128.

3. Заботин В.П. 2001. Избирательные права граждан Российской Федерации и роль органов внутренних дел в их реализации: диссертация ... кандидата юридических наук: 12.00.02. M., 215 c.

4. Иванченко А.В. 1996. Избирательные комиссии в Российской Федерации: история, теория, практика. М., Весь Мир, 304 с.

5. Карева А.В. 2018. Особенности выборов и народоправства в России: историкоправовой аспект. Выборы: теория и практика, 4 (48): 28-32.

6. Кононов А.М. 1999. Местная полиция (милиция) и местное самоуправление в России: неразрывная связь и общая история. История государства и права, 3: 43-47.

7. Любличинский, П.И. 1906. Преступления против избирательного права: выборы и уголовно-правовая защита их. СПб., 240 с.

8. Минникес И.В. 2016. История выборов в России: проблемы периодизации. Избирательное законодательство и практика, 3: 52-55.

9. Минникес И.В. 2011. Источники российского избирательного права. Вестник Бурятского госуниверситета, 2: 205-208.

10. Пузанов В.В. 2001. У истоков восточнославянской государственности. История России: Народ и власть. 459 с.

11. Российское законодательство X-XX веков: Законодательство эпохи буржуазнодемократических революций. В 9-ти томах. Т. 9. М., Юридическая литература, 1994. 352 с.

12. Сергеевич В.И. 2004. Лекции и исследования по древней истории русского права. М., Зерцало, 488 с.

\section{References}

1. Anisimov E.V. 1999. Dyba i knut. Politicheskii sysk i russkoe obshchestvo v XVIII veke. M., [Rack and whip. Political investigation and Russian society in the XVIIIth century]. Novoe literaturnoe obozrenie, $720 \mathrm{p}$. 
2. Denil'khanov A.Kh. 2018. Zarozhdenie rossiiskogo parlamentarizma: $\mathrm{k}$ voprosu o vyborakh v I-IV Gosudarstvennye Dumy Rossiiskoi imperii. [The origin of Russian parliamentarism: on the issue of elections to the I-IV State Duma of the Russian Empire]. Vlast', 26(4): 116-128.

3. Zabotin V.P. Electoral rights of citizens of the Russian Federation and the role of law enforcement bodies in their implementation: the dissertation ... of a candidate of legal sciences: 12.00.02. - M., 2001. 215 p. (in Russian)

4. Ivanchenko A.V. 1996. Izbiratel'nye komissii v Rossiiskoi Federatsii: istoriya, teoriya, praktika. [Election commissions in the Russian Federation: history, theory, practice]. M., Ves' Mir, 304 p.

5. Kareva A.V. 2018. Osobennosti vyborov i narodopravstva v Rossii: istoriko-pravovoi aspekt. [Features of elections and democracy in Russia: historical and legal aspect]. Vybory: teoriya i praktika, 4 (48): 28-32.

6. Kononov A.M. 1999. Mestnaya politsiya (militsiya) i mestnoe samoupravlenie v Rossii: nerazryvnaya svyaz' i obshchaya istoriya. [Local police (militia) and local self-government in Russia: inextricable communication and general history]. Istoriya gosudarstva i prava, 3: 43-47.

7. Lyublichinskii, P.I. 1906. Prestupleniya protiv izbiratel'nogo prava: vybory i ugolovnopravovaya zashchita ikh. [Crimes against suffrage: elections and their criminal defense]. SPb., $240 \mathrm{p}$.

8. Minnikes I.V. 2016. Istoriya vyborov v Rossii: problemy periodizatsii. [The history of elections in Russia: problems of periodization]. Izbiratel'noe zakonodatel'stvo i praktika, 3: 52-55.

9. Minnikes I.V. 2011. Istochniki rossiiskogo izbiratel'nogo prava. Vestnik Buryatskogo gosuniversiteta, 2: 205-208.

10. Puzanov V.V. 2001. U istokov vostochnoslavyanskoi gosudarstvennosti. [The history of elections in Russia: problems of periodization]. Istoriya Rossii: Narod i vlast'. 459 p.

11. Rossiiskoe zakonodatel'stvo X-XX vekov: Zakonodatel'stvo epokhi burzhuaznodemokraticheskikh revolyutsii. [Russian legislation of the 10th-20th centuries: Legislation of the era of bourgeois-democratic revolutions]. In 9 volumes. Vol. 9. Ed .: Chistyakov O.I. (Under the general ed.). M., Yuridicheskaya literatura, 1994. 352 p.

12. Sergeevich V.I. 2004. Lektsii i issledovaniya po drevnei istorii russkogo prava. [Lectures and studies on the ancient history of Russian law]. M., Zertsalo, $488 \mathrm{p}$.

\section{ИНФОРМАЦИЯ ОБ АВТОРАХ}

Вородюхин Сергей Евгеньевич, кандидат исторических наук, преподаватель кафедры государственно-правовых дисциплин Белгородского юридического института МВД России имени И.Д. Путилина, г. Белгород, Россия

Лысенко Виктория Александровна, кандидат юридических наук, начальник кафедры государственно-правовых дисциплин Белгородского юридического института МВД РФ имени И.Д. Путилина, г. Белгород, Россия

\section{INFORMATION ABOUT THE AUTHORS}

Sergey E. Vorodyukhin, candidate of Historical Sciences, lecturer at the Department of State and Legal Disciplines of the Belgorod Law Institute of the Russian Ministry of Internal Affairs named after I.D. Putilin, Belgorod, Russia

\section{Victoria.A. Lysenko}

Candidate of Legal Sciences, Head of the Department of State and Legal Disciplines of the Belgorod Law Institute of the Ministry of Internal Affairs of the RF named after I.D. Putlin, Belgorod, Russia 